\title{
Transgenic plants of Petunia hybrida harboring the CYP2E1 gene efficiently remove benzene and toluene pollutants and improve resistance to formaldehyde
}

\author{
Daoxiang Zhang, Taihe Xiang, Peihan Li and Lumin Bao \\ College of Life and Environmental Sciences, Hangzhou Normal University, Hangzhou, China.
}

\begin{abstract}
The CYP2E1 protein belongs to the P450 enzymes family and plays an important role in the metabolism of small molecular and organic pollutants. In this study we generated CYP2E1 transgenic plants of Petunia using Agrobacterium rhizogenes K599. PCR analysis confirmed that the regenerated plants contained the CYP2E1 transgene and the ro/B gene of the Ri plasmid. Southern blotting revealed the presence of multiple copies of CYP2E1 in the genome of transgenic plants. Fluorescent quantitative PCR revealed exogenous CYP2E1 gene expression in CYP2E1 transgenic plants at various levels, whereas no like expression was detected in either GUS transgenic plants or wild-types. The absorption of benzene and toluene by transgenic plants was analyzed through quantitative gas chromatography. Transgenic plants with high CYP2E1 expression showed a significant increase in absorption capacity of environmental benzene and toluene, compared to control GUS transgenic and wild type plants. Furthermore, these plants also presented obvious improved resistance to formaldehyde. This study, besides being the first to reveal that the CYP2E1 gene enhances plant resistance to formaldehyde, also furnishes a new method for reducing pollutants, such as benzene, toluene and formaldehyde, by using transgenic flowering horticultural plants.
\end{abstract}

Key words: Petunia hybrida, CYP2E1 gene, benzene, toluene, formaldehyde.

Received: May 1, 2011; Accepted: June 2, 2011.

\section{Introduction}

Benzene and toluene are common chemical components in paints, dyes, adhesives, wallpapers, carpets, synthetic fibers and detergents. Furthermore, formaldehyde is a main pollutant in the process of room decoration. These three chemicals are considered as the major hazardousgases in indoor environments. In addition, besides being highly carcinogenic, benzene and toluene can be produced by facsimile machines, computer terminals and printers. Furthermore, tobacco smoke and gasoline exhaust also contain high levels of benzene and toluene (Shen et al., 2001; Abhilash et al., 2009). Although increased ventilation by opening windows may reduce the risk of pollution, the release process itself can be extremely slow (Isbell et $a l ., 2005)$, thereby placing in great risk those living in a polluted indoor environment.

Using plants to clean chemical air pollution is economic, effective and non-destructive. There are two steps in the purification of chemical air-pollution, viz., the withholding process, which involves plant interception, absorption and retention, and the removal process, through plant

Send correspondence to Taihe Xiang. College of Life and Environmental Sciences, Hangzhou Normal University no. 16, Xuelin Street, Hangzhou City 310036, Zhejiang Province, China. E-mail: xthcn@163.com, xthcn@hznu.edu.cn. absorption, degradation, transformation, assimilation, and ultra-assimilation (Liao et al., 2007; Kavamura and Esposito, 2010). Although some natural plants have the capacity to decompose and purify, this is usually extremely inefficient. Nevertheless, efficiency can be effectively improved by way of the transgenic technique (Hu et al., 2005; Van Aken, 2008).

Cytochrome P450 2E1 is a decomposition enzyme in mammalian liver, with the strong and specific capacity of decomposing organic pollutants in animal bodies (Lee et al., 1996; Gonzalez, 2007). The Doty group at the University of Washington successfully transferred the cytochrome P450 2E1 gene (CYP2E1) into the model plants tobacco and poplar. Transgenic tobacco efficiently decomposed benzene, toluene, trichloroethylene, chloroform, carbon tetrachloride, and bi-vinyl chloride, whereas the transgenic poplar exhibited increased removal rates of trichloroethylene, vinyl chloride, carbon tetrachloride, benzene, and chloroform. The latter also demonstrated superior removal of air pollutants, when exposed to gaseous trichloroethylene, chloroform, and benzene (Doty et al., 2000, 2007; Banerjee et al., 2002; James et al., 2008). These studies opened the door to a new method of reducing environmental threats by air pollution. 
Petunia hybrida is a perennial plant, known as the "king of parterre flowers". It can be planted not only on the ground to arrange parterres, but also in hanging pots to beautify balconies. It is much-loved and widely grown worldwide (Dai and Bao, 2004). In this study we successfully transferred a CYP2E1 gene into Petunia hybrida, thus obtaining transgenic Petunia plants that could efficiently remove benzene and toluene, besides improving resistance to formaldehyde.

\section{Material and Methods}

\section{Material}

The QL01 variety of Petunia hybrida was used in this study. Sterilized seedlings were obtained by leaf in vitro tissue culture. The wild-type Agrobacterium rhizogenes K599 was raised in our laboratory, and the pSLD50-6 plasmid containing a CYP2E1, as well as the pKH200 plasmid containing the control GUS gene, were kindly provided by Dr. Doty at the University of Washington.

\section{Transformation of pSLD50-6 and pKH200 plasmids into Agrobacterium rhizogenes K599}

The freeze-thaw method was used to transform the pSLD50-6 and pKH200 plasmids into Agrobacterium rhizogenes K599. $0.1 \mu \mathrm{g}$ of purified plasmid DNA was evenly mixed within $100 \mu \mathrm{L}$ of K599 competent cells, and the mixture was put on ice for $10 \mathrm{~min}$, followed by $5 \mathrm{~min}$ of quick freezing in liquid nitrogen and 5 min of heat shock in a water bath at $28{ }^{\circ} \mathrm{C}$. Then, $500 \mu \mathrm{L}$ of LB medium was added to the mixture, which was cultured for $2 \mathrm{~h}$ with slow shaking at $28^{\circ} \mathrm{C}$. Finally, $100 \mu \mathrm{L}$ of bacteria solution was poured onto LB plates containing $50 \mathrm{mg} / \mathrm{L}$ of kanamycin $(\mathrm{Km})$ and $50 \mathrm{mg} / \mathrm{L}$ of streptomycin (Str), and cultured for $48 \mathrm{~h}$ at $28^{\circ} \mathrm{C}$.

\section{Induction of transgenic hairy roots and regeneration of Petunia plants}

The modified leaf-disk method, previously described by Wang and Xiang (2009), was used to genetically transform leaf explants of Petunia. Specimens of Agrobacterium rhizogenes K599 bearing either pSLD50-6 or pKH200, were activated on LB plates with $50 \mathrm{mg} / \mathrm{L}$ of $\mathrm{Km}$ and $50 \mathrm{mg} / \mathrm{L}$ of Str. Single colonies were then selected for overnight culture in liquid medium containing $50 \mathrm{mg} / \mathrm{L}$ of $\mathrm{Km}$ and $50 \mathrm{mg} / \mathrm{L}$ of Str, with constant shaking at $200 \mathrm{r} / \mathrm{min}$. Subsequently, $1 \mathrm{~mL}$ of bacteria solution was transferred to $50 \mathrm{~mL}$ of an MS medium containing $50 \mathrm{mg} / \mathrm{L}$ of $\mathrm{Km}$ and $50 \mathrm{mg} / \mathrm{L}$ of Str, for culture at $28{ }^{\circ} \mathrm{C}$ with $200 \mathrm{r}$ /min shaking until the $\mathrm{OD}_{600}$ reached around 0.5. All the bacteria were then spun down and washed 3 times with MS medium. Under aseptic conditions, wounded leaves, which had been pre-cultured on MS medium containing $20 \mathrm{mg} / \mathrm{L}$ of As (acetosyrinone), were infected by bacteria for $8 \mathrm{~min}$. After infection, the leaves were transferred to solid MS medium containing $20 \mathrm{mg} / \mathrm{L}$ of As and cultured for 3 days. Afterwards, they were washed 3 times with MS medium containing $500 \mathrm{mg} / \mathrm{L}$ of Cef (cefotaxime sodium), before transferred to the selection MS medium with $1.0 \mathrm{mg} / \mathrm{L}$ of $6-\mathrm{BA}, 50 \mathrm{mg} / \mathrm{L}$ of $\mathrm{Km}$, and $500 \mathrm{mg} / \mathrm{L}$ of Cef. After hairy roots had been induced and grown to about $2 \mathrm{~cm}$ in length, they were transferred to a fresh MS medium containing $500 \mathrm{mg} / \mathrm{L}$ of Cef and $50 \mathrm{mg} / \mathrm{L}$ of $\mathrm{Km}$, to eliminate bacteria and reproduce.

Based on the sequences of the CYP2E1 gene (GenBank accession number: M15061), GUS gene (GenBank accession number: AF354045) and rolB gene (GenBank accession number: X64255), the following primers were designed: CYP2E1-P1: 5'- TGA AGG GTG TGCA GCC GAT GAC AA -3', and CYP2E1-P2: 5'- CAT CGG GAA TCT TCT CCA GTT GG -3'; GUS-P1: 5'CTG CGA CGC TCA CAC CGA T -3', and GUS-P2: 5'TCA CCG AAG TTC ATG CCA GTC CAG -3'; rolB-P1: 5'- GCC AGC ATT TTT GGT GAA CT -3' and rolB-P2: 5'- CTG GCC CAT CGT TCT AAA AAA -3'. PCR analysis following the protocol described by Wang and Xiang (2009) were performed to identify transgenic hairy roots.

After sterilization and reproduction, hairy roots were cultured on MS medium containing $1.0 \mathrm{mg} / \mathrm{L}$ of 6-BA to induce calluses, which were used to generate multiple shootclumps on MS medium with $1.0 \mathrm{mg} / \mathrm{L}$ of $6-\mathrm{BA}$ and $0.4 \mathrm{mg} / \mathrm{L}$ of NAA. These clumps were cultured on MS medium supplemented with $0.1 \mathrm{mg} / \mathrm{L}$ of NAA, to thus obtain entire plants. In addition, PCR amplification was employed to identify the regenerated plants, as previously done with hairy roots.

Genomic DNA of transgenic plants, first digested with EcoRI at $37{ }^{\circ} \mathrm{C}$ overnight, was separated in $0.8 \%$ agarose gel and transferred to a nylon membrane. DNA fragments, amplified from genomic DNA with primers of CYP2E1-P1 and CYP2E1-P2, were used for preparing the probe. Probe labeling and hybridization were with the DIG DNA Labeling and Detection Kit (Roche Co.), according to manufacturer's instructions. Finally, hybridization results were scanned for the record.

\section{Fluorescent quantitative RT-PCR analysis of CYP2E1 genes in transgenic Petunia plants}

Plant total RNA was extracted and cDNA produced by means of the RevertAid First Strand cDNA Synthesis Kit from Fermentas Co. The amplification reagent for fluorescent quantitative PCR was the SYBR Green Realtime PCR Master Mix from TaKaRa Inc. The following primers were designed for amplifying Petunia GAPDH as reference gene (GenBank accession number: GQ122207): GAPDHF: 5'- AGC AAG GCA GTT AGT GGT GCA -3'; and GAPDH-R: 5'- TTG TGA TCT CCG CTC CTA GCA -3'. Based on the CYP2E1 gene sequence, the following primers were designed for specific quantitative analysis: CYP2E1-F: 5'- ATT CCC AAG TCC TTT GGC AGG -3'; 
and CYP2E1-R: 5'- TGT GGT TCA ACA GCA TCT CCC -3 '. Real-time PCR reactions were carried out in a Roche LightCycler 480 PCR machine, under the following conditions: $95^{\circ} \mathrm{C}$ for $2 \mathrm{~min}$, followed by 40 cycles of $95^{\circ} \mathrm{C}$ for $30 \mathrm{~s}, 59^{\circ} \mathrm{C}$ for $30 \mathrm{~s}$ and $72^{\circ} \mathrm{C}$ for $20 \mathrm{~s}$, whereupon the reactions were then maintained at $4{ }^{\circ} \mathrm{C}$. Relative expression levels $=2^{\text {-(CT of target gene }- \text { CT of reference gene) }}$ were calculated (Schmittgen and Livak, 2008).

\section{Gas chromatography analysis of Petunia transgenic-plant benzene and toluene absorption capacity}

A $5 \mathrm{~mL}$ aliquot of MS liquid-basal medium was placed into a $20 \mathrm{~mL}$ vial for volatile organic-compound analysis (VOA) and autoclaved. In an aseptic hood, tissue aliquots of $0.75 \mathrm{~g}$ of either transgenic or control aseptic plants were added to VOA vials, with a blank control containing only medium but no plant material. The vials were sealed with plastic film and placed into an incubator at $22-24{ }^{\circ} \mathrm{C}$ with $100 \mathrm{r} / \mathrm{min}$ agitation and a photoperiod of $16 \mathrm{~h}$. One day later, $42.5 \mu \mathrm{g}$ of benzene and $15 \mu \mathrm{g}$ of toluene were added to each VOA vial with a micro-plus injector, whereupon the vials were sealed with caps with release-valves, and cultured under the same conditions for $2 \mathrm{~h}$. The first samples were then obtained by using gas-tight gas samplers, and tested with a gas chromatographer of Aglient model $6890 \mathrm{~N}$ with a column model of DB-624 $(30 \mathrm{~m} \times 0.53 \mathrm{~mm} \times 3.0 \mu \mathrm{m})$. Testing conditions were: $200{ }^{\circ} \mathrm{C}$ of inlet temperature, $250{ }^{\circ} \mathrm{C}$ of test group, 5:1 of splitting ratio, $4.0 \mathrm{~mL} / \mathrm{min}$ of constant elution with $\mathrm{N} 2$, and $60{ }^{\circ} \mathrm{C}$ of column temperature for $5 \mathrm{~min}$, whereupon the temperature was increased to $200^{\circ} \mathrm{C}$ at a rate of $20^{\circ} \mathrm{C} / \mathrm{min}$, and kept there for $5 \mathrm{~min}, 80^{\circ} \mathrm{C}$ of headspace for $30 \mathrm{~min}$. Samples for gas chromatography analysis were collected at 48, 96 and $146 \mathrm{~h}$.

\section{Testing Petunia-plant ability for resistance to formaldehyde}

Aliquots of $5 \mathrm{~mL}$ MS basal medium were poured into $20 \mathrm{~mL}$ VOA vials. In the hood, the medium was adjusted to contain $50 \mathrm{mg} / \mathrm{L}$ of formaldehyde. $0.4 \mathrm{~g}$ of CYP $2 E 1$ gene transgenic plant, $G U S$ gene transgenic plant and wild-type plant were cultured on this medium at $24-26{ }^{\circ} \mathrm{C}, 14 / 10 \mathrm{~h}$ light/ dark photoperiod and 1500-2000 Lux light.

\section{Results}

\section{Hairy-root formation and regeneration in transgenic Petunia plants}

About 10 days after infection by Agrobacterium rhizogenes, leaf-edges sprouted small white protrusions. Simultaneously, 15 days after infection, white hairy-roots appeared on the edges of cuts (Figure 1A). However, there was no root-formation on uninfected detached leaves. The hairy-roots grew well, with the formation of numerous branched roots after only 15-20 days. After a further 15 days, green calluses were induced from these roots onto MS medium containing $1.0 \mathrm{mg} / \mathrm{L}$ of 6-BA (Figure 1B). After 45 days, multiple shoot-clusters were differentiated from the calluses on MS medium containing $1.0 \mathrm{mg} / \mathrm{L}$ of 6-BA and $0.4 \mathrm{mg} / \mathrm{L}$ of NAA. These proceeded to produce roots on MS medium containing $0.1 \mathrm{mg} / \mathrm{L}$ of NAA, later forming complete plants (Figure 1C). They were finally survival-transplanted into soil (Figure 1D), where they developed a dwarf-like morphology with abundant roots. Four plants transplanted into soil flowered normally, although without setting seeds.

The CYP2E1-P1 and CYP2E1-P2 primers amplified a 410 bp band from both CYP2E1 transgenic plants and pSLD50-6 plasmids, while no PCR products were detected using these two primers for plants regenerated by tissue culture. The rolB-P1 and rolB-P2 primers amplified a band of around $450 \mathrm{bp}$ from all the 7 randomly chosen CYP2E1 transgenic plants, as well as from Ri plasmids borne by wild-type Agrobacterium rhizogenes, while no such PCR band was observed using these primers for plants regenerated by tissue culture (Figure 2A, B). A similar strategy for PCR-characterization was used to confirm GUS transgenic plants, in this case using rolB-P1, rolB-P2, GUS-P1, and GUS-P2 primers (data not shown).

Furthermore, Southern blot analysis revealed that the CYP2E1 gene had multiple copies in the genome of four survival-plants transplanted into soil, which were denominated CYP2E1-1, CYP2E1-2, CYP2E1-3 and CYP2E1-4 (Figure 2C).

\section{Fluorescent quantitative RT-PCR for CYP2E1 transgenic Petunia plants}

Fluorescent quantitative RT-PCR was undertaken for the following selected plants, with $G A P D H$ as the reference gene: the four CYP2E1 transgenic plants, CYP2E1-1, CYP2E1-2, CYP2E1-3 and CYP2E1-4; a GUS transgenic control plant; and a wild-type (non-transgenic) plant. The exogenous $C Y P 2 E 1$ gene was expressed in all the examined CYP2E1 transgenic plants, with significantly higher expression in CYP2E1-1 and CYP2E1-4, whereas no expression was detected in the GUS control and the wild type plant (Figure 3).

\section{CYP2E1 transgenic Petunia plant benzene and toluene absorption and decomposition capacity}

The absorption of benzene and toluene by transgenic plants was measured by quantitative gas chromatography. Six days later, the levels of benzene and toluene had already been significantly reduced by the CYP2E1 transgenic plant tissues of CYP2E1-1 and CYP2E1-4. GUS transgenic and wild type plants revealed no significant changes in benzene and toluene absorption (Figure 4A, B). Furthermore, there was no significant difference between CYP2E1-2 and 

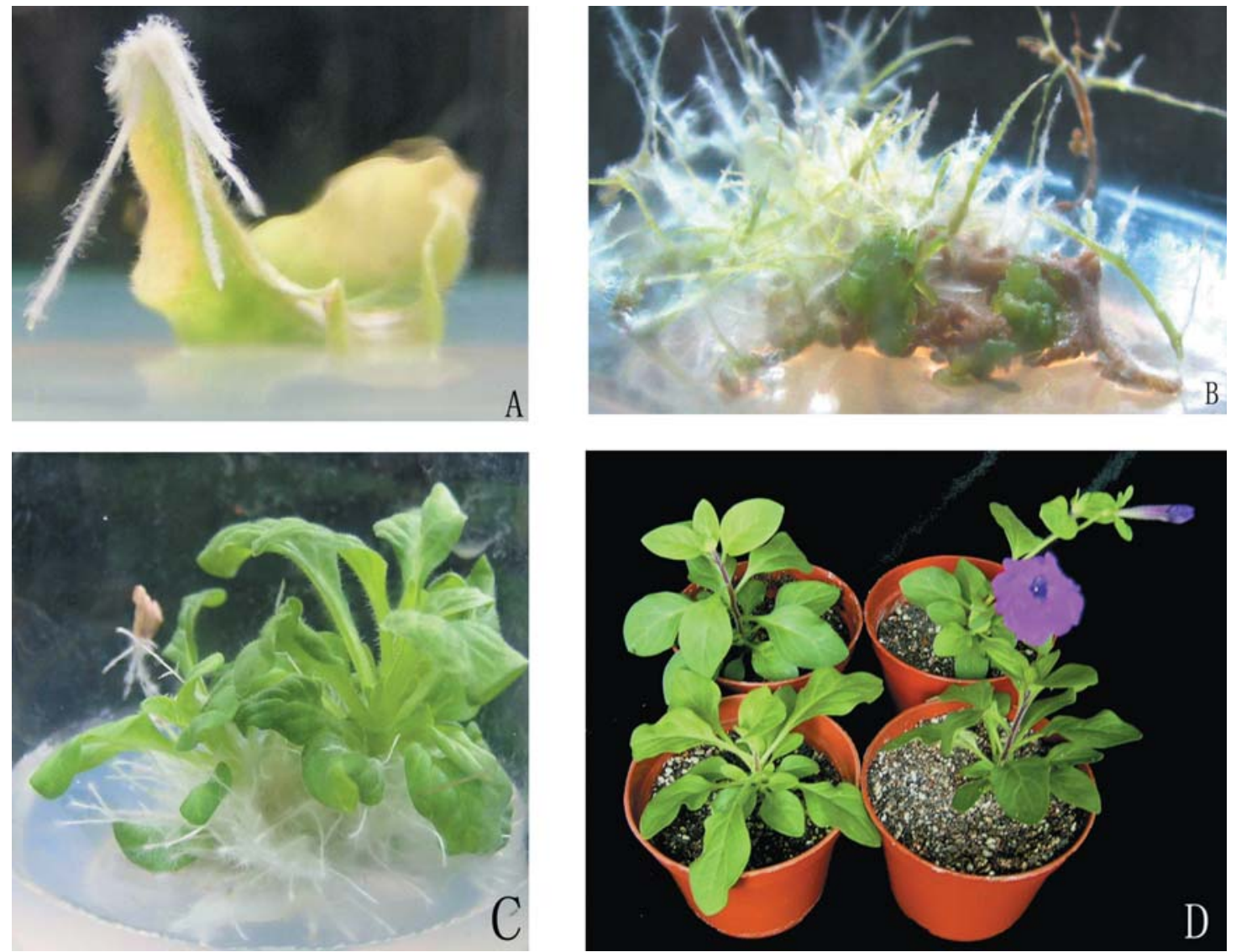

Figure 1 - Transgenic hairy roots and regenerated plants of CYP2E1 transgenic Petunia. (A) transgenic hairy roots from cuts in the edges of Petunia leaves; (B) calluses induced from transgenic hairy roots; (C) plants regenerated from calluses; (D) four transgenic plants survival-transplanted into soil.
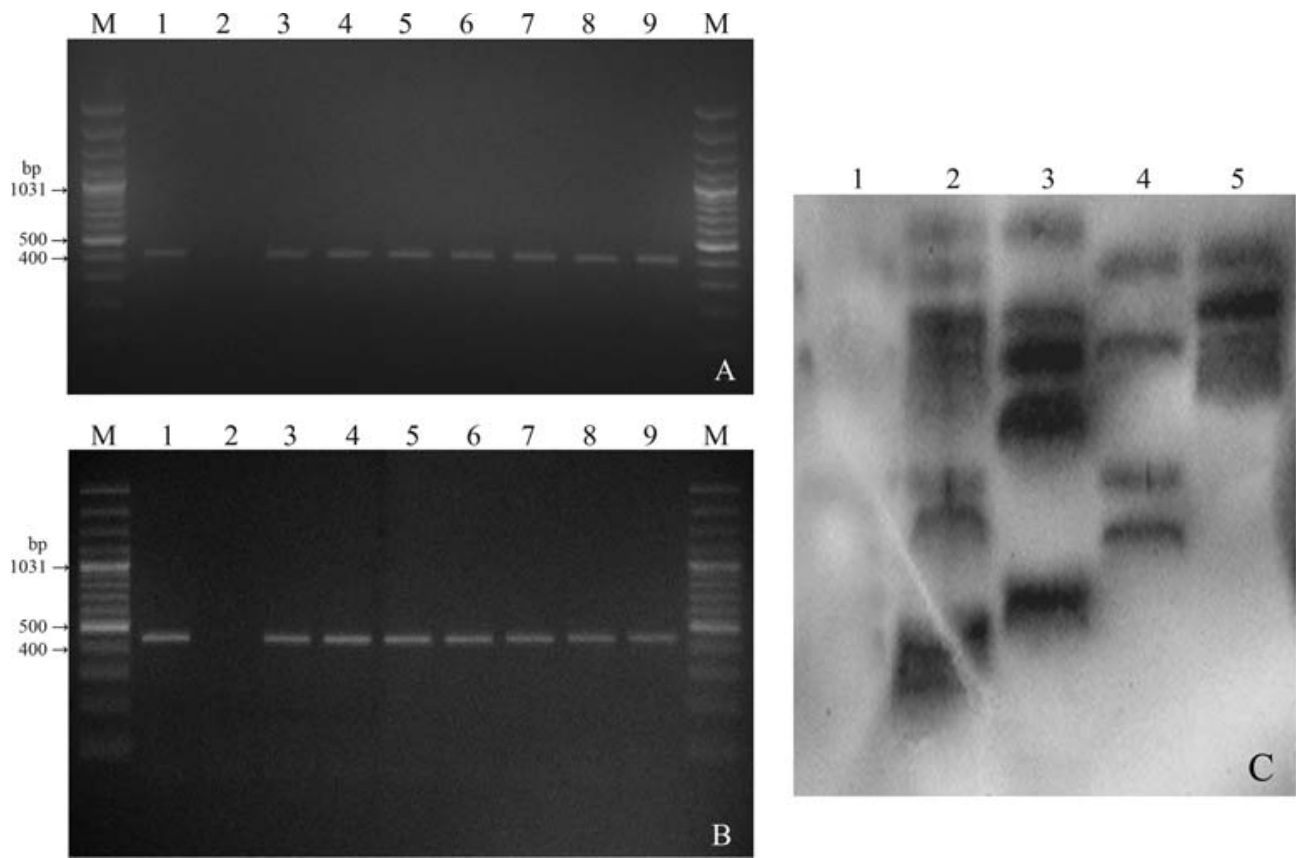

Figure 2 - Molecular identification of regenerated plants of CYP2E1 transgenic Petunia. (A) PCR amplification of CYP2E1 gene; M: 100 bp ladder plus DNA molecular marker (MBI Co.); 1: 410 bp band amplified from Ri plasmid carried by wild-type Agrobacterium rhizogenes K599; 2: no PCR bands were observed in plants regenerated by tissue culture; 3-9: 410 bp bands amplified from each of the 7 CYP2E1 transgenic plants. (B) PCR amplification of the rolB gene; M: 100 bp ladder plus DNA molecular marker (MBI Co.); 1: amplification of an approx. 450 bp band from Ri plasmids carried by wild-type Agrobacterium rhizogenes K599; 2: no PCR bands were observed in plants regenerated by tissue culture; 3-9: 450 bp bands amplified from each of the 7 CYP2E1 transgenic plants. (C) Southern blot analysis of CYP2E1 transgenic plants; 1: no bands in wild-type (non-transgenic) plants; 2-5: respective bands in CYP2E1-1, CYP2E1-2, CYP2E1-3 and CYP2E1-4 transgenic plants. 


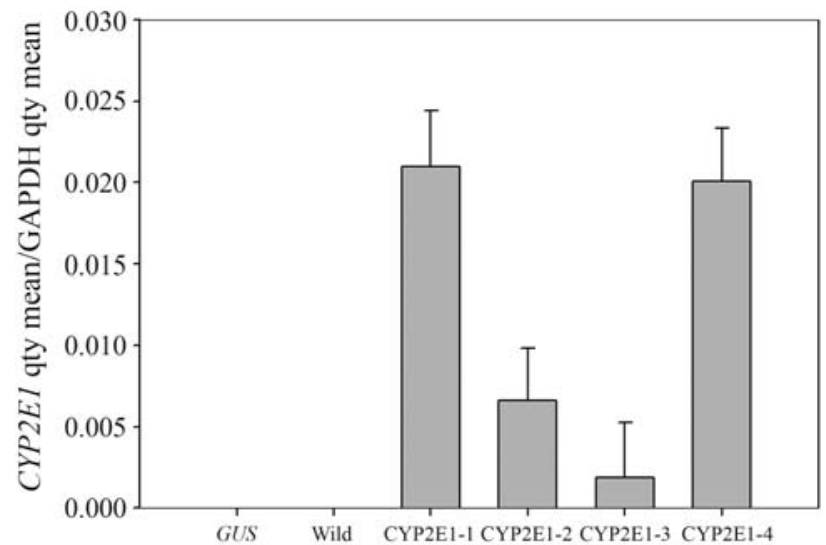

Figure 3 - Fluorescent quantitative RT-PCR analysis of CYP2E1 gene expression in CYP2E1 transgenic, GUS transgenic and wild type (nontransgenic) plants. The exogenous CYP2E1 gene, detected in all the examined CYP2E1 transgenic plants, CYP2E1-1, CYP2E1-2, CYP2E1-3 and CYP2E1-4, were especially highly expressed in two, CYP2E1-1 and CYP2E1-4, while GUS control and wild type plants did not express CYP2E1.
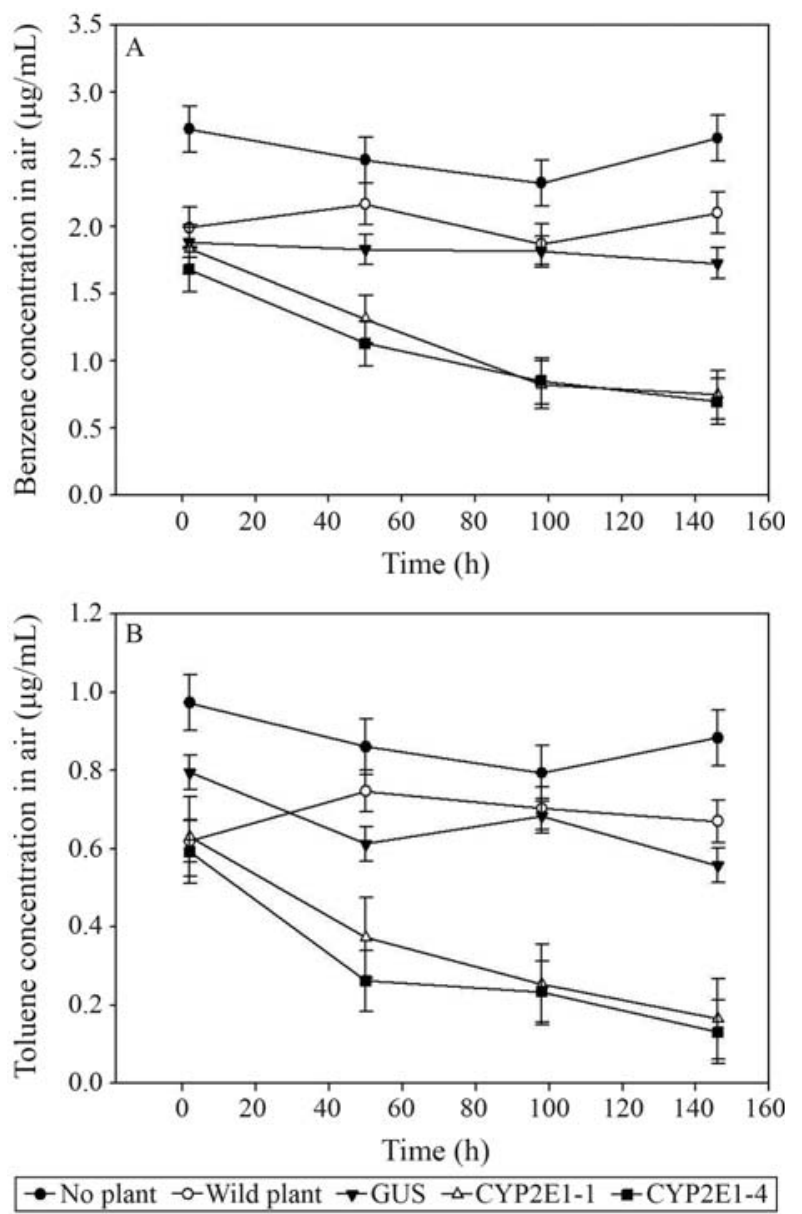

Figure 4 - Gas chromatographic analysis of benzene (A) and toluene (B) decomposition and absorption by CYP2E1 transgenic, GUS transgenic and wild-type (non-transgenic) Petunia plants. Benzene and toluene levels were significantly reduced by CYP2E1 transgenic plant tissue of CYP2E1-1 and CYP2E1-4, whereas while GUS transgenic plant and wild type plant did not show significant changes in absorption of benzene and toluene over time.
CYP2E1-3 with low-level CYP2E1 expression, and GUS transgenic and wild-type plants (data not shown).

\section{CYP2E1 transgenic Petunia plant capacity for resistance to formaldehyde}

CYP2E1-1 and CYP2E1-4 transgenic plants maintained normal growth when cultured on MS medium with $50 \mathrm{mg} / \mathrm{L}$ of formaldehyde, whereas CYP2E1-2, CYP2E13, GUS transgenic and wild-types all withered and died after 30 days (Figure 5). Transgenic Petunia plants with high CYP2E1 expression levels presented significantly improved ability for resistance to formaldehyde.

\section{Discussion}

Plants play an important role in the removal of nearsurface atmospheric pollutants. Their use is economic, effective, and non-destructive. Not only is integration with the environment easier, but plant-use can also be extended to greening and aesthetics. However, only a limited number of plants in nature possess the capacity for atmosphericpollutant decomposition and purification, efficiency is usually very low. Transgenic technology has been shown to be an effective way for improving plant environmental-remediation capacity (Hu et al., 2005; Van Aken, 2008).

CYP2E1 belongs to the P450 enzyme gene family and is specifically expressed in mammalian liver. The CYP2E1 protein plays an important role in the metabolism of small molecular and organic pollutants. The Doty group was the first to transfer the CYP2E1 gene into the model plants tobacco and poplar, both of which showed highly effective decomposing capacity for benzene, toluene, trichloroethylene, chloroform, carbon tetrachloride and vinyl chloride (Doty et al., 2000, 2007; Banerjee et al., 2002; James et al., 2008).

In this study we successfully transferred the cytochrome P450 2E1 gene into Petunia by using Agrobacterium rhizogenes transgenic technology and obtained transgenic

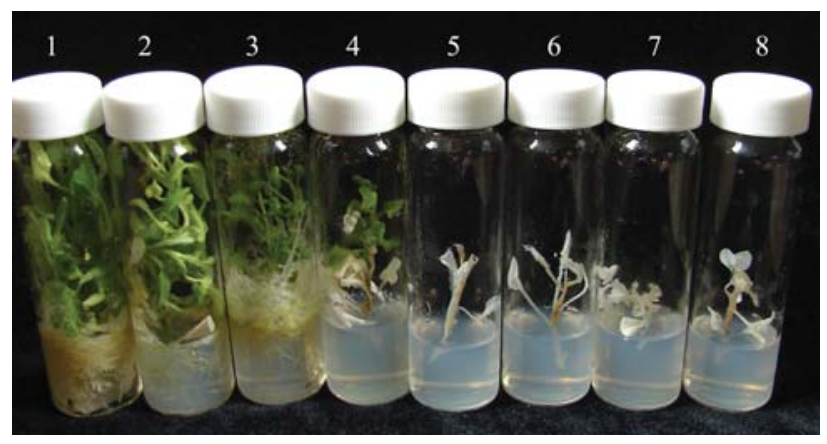

Figure 5 - CYP2E1 transgenic, GUS transgenic and wild-type plants tolerance to formaldehyde. 1,2: After 30 days, CYP2E1 transgenic plants of CYP2E1-1 continued to maintain normal growth, when cultured on MS medium with $50 \mathrm{mg} / \mathrm{L}$ of formaldehyde; 3, 4: After 30 days, CYP2E1 transgenic plants of CYP2E1-4 continued to maintain normal growth, when cultured on the same medium; 5-8: After 30 days, CYP2E1 transgenic plants of CYP2E1-2, CYP2E1-3 and wild-type and GUS transgenic plants died on MS medium with $50 \mathrm{mg} / \mathrm{L}$ of formaldehyde. 
plants with high CYP2E1 expression. The transgenic plants with high levels of CYP2E1 were efficient in removing benzene and toluene, and these plants had obviously improved ability of resistance to formaldehyde. Our study is the first one to report that the CYP2E1 gene enhances the resistance ability of plants to formaldehyde.

CYP2E1 gene expression levels in the four transgenic lines, CYP2E1-1, CYP2E1-2, CYP2E1-3 and CYP2E1-4, were different, possibly caused by different sites of insertion that silenced CYP2E1 expression in some transgenic plants. This variation is common in transgenic plants $(\mathrm{Ku}-$ mar and Fladung, 2001; Butaye et al., 2005).

Although further investigation is required, in order to understand how the CYP2E1 transgene improves plantcapacity for cleaning pollutants, it is proposed that certain specific electron transfer enzymes are produced in Petunia, so as to facilitate the CYP2E1 role in decomposing organic pollutants, as occurs with the mammalian CYP2E1 enzyme, which requires oxidoreductase NADPH-P450 and cytochrome b5 for electron transfer (Doty et al., 2007).

The transgenic Petunia plants obtained in this study have potential industrial value, through providing a novel method for reducing indoor air-pollution by benzene and toluene. In addition, transgenic plants produced by Agrobacterium rhizogenes transgenic technology presented dwarf-morphology with abundant roots, which makes this technology fit for screening novel forms of breeding material for Petunia. Furthermore, four plants transplanted into the soil could flower normally, but were incapable of forming seeds. Whether this phenomenon is related to CYP2E1 transgenis will have to be addressed in subsequent studies.

\section{Acknowledgments}

The project was supported by the Zhejiang Provincial Natural Science Foundation (No. Y3080184) and the Hangzhou Science and Technology Development Plan (No. 20091133B07).

\section{References}

Abhilash PC, Jamil S and Singh N (2009) Transgenic plants for enhanced biodegradation and phytoremediation of organic xenobiotics. Biotechnol Adv 7:474-488.

Banerjee S, Shang TQ, Wilson AM, Moore AL, Strand SE, Gordon MP and Doty SL (2002) Expression of functional mammalian P450 2E1 in hairy root cultures. Biotechnol Bioeng 77:462-466.

Butaye K, Cammue B, Delauré S and De Bolle M (2005) Approaches to minimize variation of transgene expression in plants. Mol Breed 16:79-91.
Dai SP and Bao MZ (2004) Advances in genetics and breeding of Petunia hybrida Vilm. Chin Bull Bot 21:385-391 (in Chinese, Abstract in English).

Doty SL, James CA, Moore AL, Vajzovic A, Singleton GL, Ma C, Khan Z, Xin G, Kang JW, Park JY, et al. (2007) Enhanced phytoremediation of volatile environmental pollutants with transgenic trees. Proc Natl Acad Sci USA 104:16816-16821.

Doty SL, Shang QT, Wilson AM, Westergreen AD, Newman LA, Strand SE and Gordon MP (2000) Enhanced metabolism of halogenated hydrocarbons in transgenic plants containing mammalian cytochrome P450 2E1. Proc Natl Acad Sci USA 97:6287-6291.

Gonzalez FJ (2007) The 2006 Bernard B. Brodie Award Lecture CYP2E1. Drug Metab Dispos 35:1-8.

Hu GZ, Wang YF and He YK (2005) Uptake, transformation and degradation of organic pollutants in transgenic plants. $\mathrm{J}$ Plant Physiol Mol Biol 31:340-346 (in Chinese, Abstract in English).

Isbell MA, Stolzberg RJ and Duffy LK (2005) Indoor climate in interior AK: Simultaneous measurement of ventilation, benzene and toluene in residential indoor air of two homes. Sci Total Environ 345:31-40.

James CA, Xin G, Doty SL and Strand SE (2008) Degradation of low molecular weight volatile organic compounds by plants genetically modified with mammalian cytochrome P450 2E1. Environ Sci Technol 42:289-293.

Kavamura VN and Esposito E (2010) Biotechnological strategies applied to the decontamination of soils polluted with heavy metals. Biotechnol Adv 28:61-69.

Kumar S and Fladung M (2001) Controlling transgene integration in plants. Trends Plant Sci 6:155-159.

Lee SS, Buters JT, Pineau T, Fernandez-Salguero P and Gonzalez FJ (1996) Role of CYP2E1 in the hepatotoxicity of acetaminophen. J Biol Chem 271:12063-12067.

Liao XY, Chen TB, Yan XL and Nie CJ (2007) Enhancement of heavy metal removal in phytoremediation of soils contaminated with heavy metals. Acta Scient Circum 27:881-892 (in Chinese, Abstract in English).

Schmittgen TD and Livak KJ (2008) Analyzing real-time PCR data by the comparative C(T) method. Nat Protoc 3:11011108.

Shen XY, Luo XL and Zhu LZ (2001) Progress in research on volatile organic compounds in ambient air. J Zhejiang Univ (Sci Edition) 28:547-556 (in Chinese, Abstract in English).

Van Aken B (2008) Transgenic plants for phytoremediation: Helping nature to clean up environmental pollution. Trends Biotechnol 26:225-227.

Wang L and Xiang TH (2009) Cloning of flavonoid-3', 5'-hydroxylase gene (F3',5'H) of Petunia hybrida and construction of a novel vector expression F3',5'H driven by flowerspecific promoter. J Trop Subtrop Bot 17:358-364 (in Chinese, Abstract in English).

\section{Associate Editor: Carlos F.M. Menck}

License information: This is an open-access article distributed under the terms of the Creative Commons Attribution License, which permits unrestricted use, distribution, and reproduction in any medium, provided the original work is properly cited. 